\title{
Sustainability and Communication in Higher Education
}

\section{Denise Voci ${ }^{1}$, Matthias Karmasin ${ }^{1,2}$}

${ }^{1}$ Department of Media and Communications, University of Klagenfurt, Austria, ${ }^{2}$ Institute of Comparative Media and Communication Studies (CMC), Austrian Academy of Science, Austria.

\begin{abstract}
Sustainability Sciences need communication to communicate knowledge effectively and to engage audiences toward sustainable development. Therefore, the present study examines to what extent media and communication aspects are integrated into sustainability science curricula of higher education institutions in Europe. For this purpose, a total of $n=1117$ bachelor and master's degree programs and their related curricula/program specifications from 31 European countries were analyzed by means of content analysis. Results show that the level of curricular integration of media and communication aspects in the field of sustainability science is not (yet) far advanced (18\%). This leaves room for a reflection on the perceived (irrelevance of communication as a crucial discipline and competence in the sustainability science area, as well as on the social and educational responsibility of higher education institutions.
\end{abstract}

Keywords: Sustainability science; higher education; media and communication, third mission, sustainability communication. 


\section{Introduction}

In recent years, sustainability has increasingly occupied a prominent role in our society, developing from the buzzword of the last decade to a fundamental concept in finding a new balance between the ecosystem and society. Nonetheless, in observing current societies, it is evident that current paradigms, deeply anchored in our (economic and social) system, contribute rather to an unsustainable development. In this regard, education can play a decisive role. As historically demonstrated several times, universities and higher education institutions in general have driven social change both through scientific breakthroughs as well as through the opportunity to train and educate the next generation of intellectuals and future makers (Cortese, 2003). In terms of a comprehensive responsibility, universities must therefore recognize current, future, and socially relevant topics and include them in their teaching programs (Mintz \& Tal, 2013). Consequently, if universities want to contribute to sustainability meaningfully, this relevant issue has to be integrated into their study programs (Tilbury, 2011).

As one of our time's most significant challenges, sustainability, sustainable development, and the achievement of the 17 Sustainable Development Goals (SDGs) seem to have already reached higher education, as the various range of so-called "Sustainable Science" study programs shows. Sustainability Science is defined as a transdisciplinary academic field that helps understand and contribute to solutions "for complex challenges that threaten the future of humanity and the integrity of the life support systems of the planet, such as climate change, biodiversity loss, pollution and land, and water degradation" (ESG, 2021), by integrating research from natural, engineering, medical, social sciences, and humanities. So, while it is clear that higher education institutions recognized the need for sustainability science education and fulfill this way their responsibilities in the sense of responsible science, as part of their "third mission"1 it also becomes clear how dominant research modes are not enough to guide the societal transformation necessary to achieve the 2030 agenda (Messerli et al., 2019). Here the role of communication becomes particularly relevant since "knowledge alone does not motivate action" (Mullholland, 2019, p. 7). However, it is not just about the question of how scientists can communicate more effectively what they know, how they know it, and how sure they are of it (Hassol, 2008). Knowledge transfer or creating awareness through traditional and/or social media is just the initial part of it. Instead, communication is required to initiate a whole-of-society transformation process toward sustainable development. Indeed, communication has the ability to engage audiences, as "communication

\footnotetext{
${ }^{1}$ For a definition and further information, see, e.g., Zomer and Benneworth, 2011; Trencher et al., 2014; Pinheiro et al., 2015.
} 
and behavior are linked, and behavior cannot change without communication" (Karmasin et al., 2021).

Against this background, the study at hand examines to what extent communication and media aspects are integrated into sustainability science curricula of European post-secondary institutions. Thus, $n=117$ bachelor and master degree programs and their related curricula from 31 European countries were analyzed by means of content analysis. Looking at curricula is relevant from a heuristic perspective and helps verify whether Humboldt's ideal model of education is maintained in tertiary education. The analysis also provides information on to what extent sustainability sciences have already recognized and integrated the need for effective communication in their teaching programs.

\section{From Sustainable Development to Sustainability Science}

The central role of higher education for the promotion of sustainable development was addressed and identified by the United Nations as early as 1972 at the "United Nations Conference on the Human Environment" (UNCHE) (UN Documents, 2020). This was followed by numerous other conferences and official documents that further emphasized this role, such as the "Belgrade Charter" 1975 (UNEP, 1975), the "Tbilisi Declaration" 1977 (UNESCO, 1977), the Brundtland Report - which particularly emphasizes the teacher's role (WCED, 1987) - and the Agenda 21 (UN 1992). More recent examples are the so-called "Ubuntu Declaration" 2002 (UN, 2002), the global plan of action "Education for sustainable development" 2005 (UNESCO, 2005), or the SDGs mentioned above (UN, 2015). However, the duty to (higher) education to contribute towards sustainable development did not only come as an attribution of responsibility from policy. Instead, there has been a significant increase in self-commitment since the 1990s, starting with the Talloires Declaration 1990 the first official statement made by university presidents for incorporating sustainability in teaching and research (ULSF, 1990). All these (self-)commitment by higher-education institutions to support and promote sustainable development led to establishing the new research area of "Sustainability Sciences". However, communication's key role as a central process to optimize knowledge transfer, engage audiences, and initiate societal transformation processes toward sustainable development is even largely ignored here. This is the starting point of the presented study, aiming to analyze what role communication plays in sustainability science curricula.

The analysis of curricula as well as of curricular change processes are traditionally seen as an essential decision-making process in and for higher education management (see, e.g., Drake, 1998) since the curriculum is mainly perceived as an educational project that is developed in a specific historical, social and political context and has the ability to form identities. In addition, sustainability-related formal changes - such as curricular changes - 
are considered to be more successful than informal, non-binding measures (Cortese, 2003). Furthermore, suppose we understand communication as a core dynamic of social behavior and consider the importance of communication - primarily through media - in the construction and communication of risks and crises and the attempts to achieve attitude and behavioral change. In that case, the investigation of how communication aspects are integrated into sustainability science curricula should be seen as essential.

\section{Methodology}

The presented study aims to analyze the extent to which media and communication aspects are integrated into the sustainability science curricula of post-secondary institutions in Europe. ${ }^{2}$ To this purpose, we analyzed $n=1117$ English-language bachelor and master degree programs and their related curricula/program specifications by means of content analysis. The sample results from a keyword search on the leading study choice platforms at the European level: For study programs on a bachelor level on www.bachelorsportal.eu, while for master degree programs on www.masterportal.com. ${ }^{3}$ The keywords used to identify sustainability sciences study programs were chosen in line with the definition of the academic field mentioned above (see ESG, 2021): sustain*, environment*, ecol*, clima*, natur*, resource ${ }^{*}$, and green. As a result of this process, a total of $n=270$ bachelor and $n=847$ master study programs in the sustainability science's field in 31 European countries ${ }^{4}$ were included in the sample.

To investigate to what extent communication aspects are integrated into sustainability science curricula, we also took a closer look at online content. We analyze the study program's description on the official website and the curriculum/program specification, including the detailed course descriptions through content analysis. For this purpose, we ran a second keyword search. The keywords used were: media, communicat* ${ }^{*}$,journal* ${ }^{*}$, public relations, publish $*$ and report ${ }^{*}$. For each hit, the corresponding paragraph was analyzed by means of qualitative content analysis, following an inductive approach (Mayring, 2014), in order to understand the word in its context. The results are presented in the sext section.

\footnotetext{
${ }^{2}$ Europe refers here not to its political definition, i.e., a country's membership in the European Union, but Europe's geographical borders.

${ }^{3}$ Both platforms are affiliated with studyportals.com and provide information on more than 200,000 study programs offered by more than 3,750 educational institutions (studyportals, 2020).

${ }^{4}$ These are: Austria, Belgium, Croatia, Cyprus, Czech Republic, Denmark, England, Estonia, Finland, France, Germany, Greece, Iceland, Ireland, Italy, Latvia, Lithuania, Luxembourg, Malta, Netherlands, Nord Ireland, Norway, Poland, Portugal, Romania, Scotland, Slovenia, Spain, Sweden, Switzerland, Wales.
} 


\section{Results}

The results show that the level of the integration of communication and media aspects in sustainability science's curricula is not (yet) far advanced. Out of a total of $n=1117$ examined study programs and the associated curricula and/or module handbooks, communication and media aspects could only be found in $n=202$. That corresponds to $18.1 \%$. The result of $n=202$ relates to the presence of one of the keywords (media, communicat*, journal*, public relations, publish* and report*) either in the study program's description on the official institution website or in the related curriculum itself. However, in this context, a differentiation between study programs at the bachelor and master level has to be made. At a bachelor level, $n=270$ study programs and related curricula were analyzed. Here the analysis identifies 85 curricula integrating communication and media aspects. This corresponds to about a third (31.8\%). Therefore, the integration of media and communication aspects in sustainability sciences curricula is much more advanced at bachelor than at master level. Indeed, here the analysis identifies only $n=117$ curricula integrating communication. To a total of $n=847$ master's degree programs, this only corresponds to $13.8 \%$ (see Fig. 1).
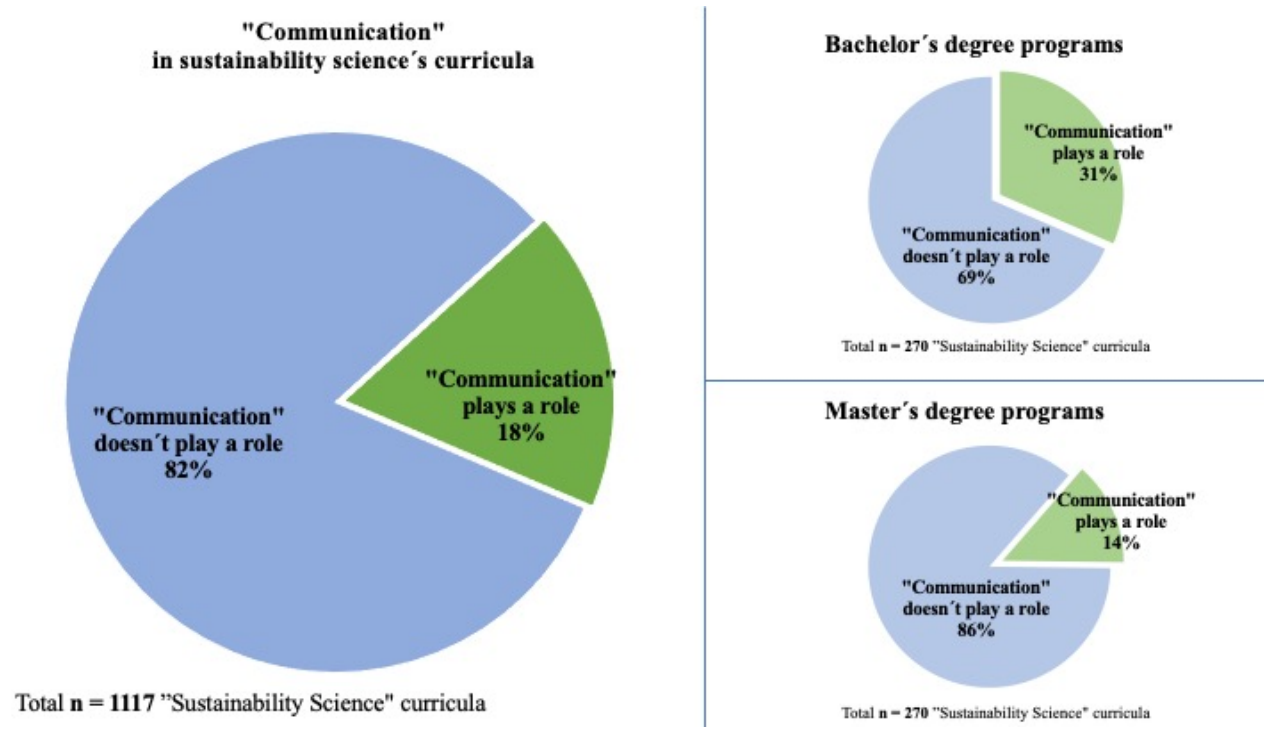

Figure 1. Communication and media aspects in sustainability science's curricula

It is noticeable that almost half of the study programs that integrate communication aspects can be assigned to the field of "Natural Sciences" (47\%), while $20 \%$ of the study programs integrating communication aspects can be assigned to the area of "Social Sciences" and 16\% to the area of "Engineering Sciences".

The aim of the present work is, however, is to investigate whether and to what extent communication and media aspects are integrated into higher education teaching. For this 
purpose, the analysis was set one level lower, i.e., analyzing whether specific modules are dedicated to communication and/or media-related aspects. The analysis at module level shows that out of $n=202$ study programs and related curricula that integrate sustainability issues, $n=119(58,9 \%)$ also offer a total of 164 modules dedicated to communication and/or media aspects, of which 74 are offered at a bachelor and 90 at a master level.

Summarizing, this means: the analysis on a modular level reveals that the extent of the integration of communication and media aspects into higher education teaching of sustainability sciences study programs is equal to $10,6 \%$ (Fig. 2).

\section{“Communication" in sustainability science's curricula - module level}

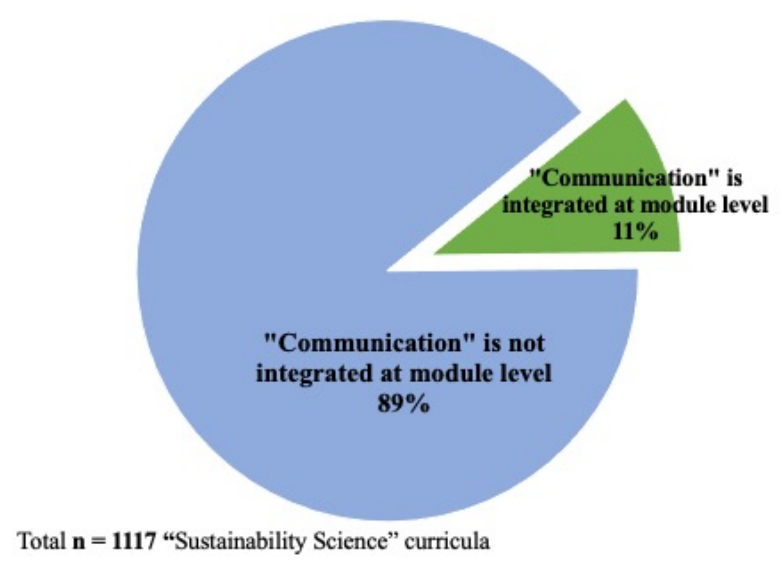

Figure 2. “Communication” in sustainability science's curricula-module level.

\section{Discussion}

The study at hand analyses the extent to which communication and media aspects are integrated into sustainability science curricula of European post-secondary institutions. The analysis reveals a relatively low (18\%) degree of integration, which is further reduced at the module level $(10,6 \%)$. The results can be interpreted as a confirmation of ignoring communication as a key discipline for and in the sustainability area, as practiced by policy and institutions in their action initiatives, as mentioned above (Chapter 2). However, a closer look at the data could also reveal a quite different picture. The integration of communication aspects is more advanced at the bachelor level (31.5\%). So, if we assume that basic skills are imparted during a bachelor's degree, it can be said that communication is already recognized as fundamental competence in the sustainability science field of sustainability science, which enables studying at a master level. Of course, further and more specialized education in the 
framework of master's degrees is desirable and needed since it can be assumed that students who have enjoyed a specialized education - i.e., those holding a master's degree - are more likely to be employed in leading positions, and thus have greater possibilities to engage audiences and stimulate a turnaround toward sustainable development in the near future.

The analysis shows that the journey in this direction will be a long one, though the results at the bachelor level are encouraging and suggest that the right direction has already been taken. Furthermore, the presented analysis should be understood as an opportunity to reflect on the conception of (media and) communication studies, especially regarding the discipline's attributed social relevance. (Media and) communication science has the potential to make a substantial contribution to the "third mission" of higher education institutions, in the sense of public outreach and responsible science, and needs to be positioned at the core of sustainability sciences. How the knowledge produced by sustainability science is communicated is as important as the content of that communication itself since communication can engage audiences so that they shift "from passive listeners to conscious actors of change" (Karmasin et al., 2021).

In conclusion, the authors are aware that not all teaching content is and can be displayed by curricula and program specifications. Nonetheless, the presented analysis should be seen as a first step to represent the status quo of the integration degree of communication and media aspects in sustainability science's curricula and highlight the related issues of a low integration level. Furthermore, the limitation of analyzing solely English-language curricula has to be pointed out. Further research in this area is needed in order to clarify whether this low integration level also occurs in "native-language" study programs.

\section{References}

Cortese, A. D. (2003). The Critical Role of Higher Education in Creating a Sustainable Future. Planning for Higher Education, Vol. March-May 2003, 15-22.

Drake, S. M. (1998). Creating Integrated Curriculum: Proven Ways to Increase Student Learning. Thousand Oaks: Corwin Press.

ESG - Earth System Governance (2021). Sustainability Science. Retrieved from: https://www.earthsystemgovernance.net/conceptual-foundations/?page_id=73

Hassol, S. J. (2008). Improving How Scientists Communicate About Climate Change. Eos, 89(11), 106-107. doi: 10.1029/2008EO110002.

Karmasin, M., Voci, D. Weder, F., \& Krainer, L. (2021). Future Perspectives: Sustainability Communication as scientific and societal challenge. In F. Weder, L. Krainer, \& M. Karmasin (Eds.), The Sustainability Communication Reader. A Reflective Compendium. Wiesbaden: Springer. doi: 10.1007/978-3-658-31883-3

Mayring, P.H. (2014). Qualitative Inhaltsanalyse, Grundlagen Und Techniken, 12th ed., Beltz, Weinheim. doi: 10.1007/978-3-531-18939-0_38 
Messerli, P., Kim, E. M., Lutz, W., et al. (2019). Expansion of sustainability science needed for the SDGs. Nature Sustainability, 2, 892-894. doi: https://doi.org/10.1038/s41893019-0394-z.

Mintz, K., \& Tal, T. (2013). Sustainability in higher education courses: Multiple learning outcomes. Studies in Educational Evaluation, 41, 113-123.

Mulholland, E. (2019). Communicating Sustainable Development and the SDGs in Europe: Good practice examples from policy, academia, NGOs, and media. ESDN Quarterly Report 51. Retrieved from: https:/www.sdnetwork.eu/quarterly\%20reports/report\%20files/pdf/2019-January-

Communicating_Sustainable_Development_and_the_SDGs_in_Europe.pdf.

Pinhero, R., Langa, P. V., \& Pausits, A. (2015). The institutionalization of universities' third mission: introduction to the special issue. European Journal of Higher Education, 5(3), 227-232.

Studyportals (2020). About. Retrived from: https://studyportals.com/about-us/

Tilbury, D. (2011). Higher Education for Sustainability: A Global Overview of Commitment and Progress. Higher Education in the World, 4(1), 18-28.

Trencher, G., Yarime, M., McCormick, K. B., Doll, C. N., \& Kraines, S. B. (2014). Beyond the third mission: Exploring the emerging university function of co-creation for sustainability. Science and Public Policy, 41(2), 151-179.

ULSF - University Leaders for a Sustainable Future (1990). The Talloires Declaration. Retrieved from: http://ulsf.org/talloires-declaration/

UN - United Nations (2015). 4 - Ensure inclusive and equitable quality education and promote lifelong learning opportunities for all. Retrived from: https://sdgs.un.org/goals/goal4

UN - United Nations (2002). Report of the World Summit on Sustainable Development. Johannesburg, South Africa. Retrived from: https://digitallibrary.un.org/record/478154

UN - United Nations (1992). AGENDA 21. Retrived from: https://sustainabledevelopment.un.org/content/documents/Agenda21.pdf

UN Documents (2020). Declaration of the United Nations Conference on the Human Environment", Retrieved from: http://un-documents.net/unchedec.htm

UNEP - United Nations Environment Programme (1975). The Belgrade Charter: A Framework for Environmental Education. Retrived from: https://unesdoc.unesco.org/ark:/48223/pf0000017772

UNESCO (2005). UN Decade of ESD. Retrived from: https://en.unesco.org/themes/education-sustainable-development/what-is-esd/undecade-of-esd

UNESCO (1977). International Conference on Environment Education. Final Report. Tiflis (USSR), 14-16 Oktober 1977. Retrived from: https://www.gdrc.org/uem/ee/TbilisiDeclaration.pdf

WCED - World Commission on Environment and Development (1987). Our Common Future. Oxford: Oxford University Press. 
Zomer, A., \& Benneworth, P. (2011). The rise of the university's third mission. In J. Ender, H. F. de Boer, \& D. F. Westerheijden (Eds.), Reform of higher education in Europe (pp. 81-101). Rotterdam: Sense Publishers. 